\title{
The Effect of Talent Management Strategies Achievement on Organizational Agility with Governmental Institutions Employees in the Governorate of MA'AN
}

\author{
Dr. Dua'a Shaher Tobeery \\ Al-Hussein Bin Talal University, Jordan
}

doi: 10.19044/esj.2017.v13n23p316 URL:http://dx.doi.org/10.19044/esj.2017.v13n23p316

\begin{abstract}
This study aimed at identifying the effect of talent management strategies carrying out, on organizational agility among governmental employees in the governorate of MA'AN. The population of the study consists of employees working at upper and middle management levels in government agencies in the governorate of MA'AN. They were (112) manager. In order to achieve the objectives of the study, a questionnaire has been developed, and distributed over the study's participants. Results revealed the presence of talent management strategies' effect in accordance with its variables on organizational agility. Based upon the results, the study recommends the following: It is necessary for governmental institutions to be concerned with talent management, and activate it due to its effect on enhancing organizational agility, as it is shown in the participants' responses.
\end{abstract}

Keywords: Talent Management, Organizational Agility, Ma'an

\subsection{Introduction}

The development which business administration has experienced recently, and modern day's requirements of quality and differentiated performance, have led organizations to acquire talented human resources who possess higher abilities and superior skills. Such a talented workforce is considered to be the versatile source for creativity, innovation, differentiation and organizational leadership necessary for success Source: Park, Young Ki, (2011).

Such a source has to be dealt with in a special way; this type of dealing with talented employees has resulted in the evolution of the talent management concept. This concept has become one of the new concepts of human resources in modern times for organizations' performance enhancement. 
Due to the importance of the talent management concept in the life of organizations, this concept has started receiving attention by organizations. In addition to its importance, this concept focuses on the interest in effective abilities, talents and skills within human resources. For these reasons organizations' interest in this concept increased and consequently, talent management has become very important in work organization and assignments , and one of the key changes in differentiation strategies Kasmi Zartaj, (2011).

Since talent has become an integral part of organization in order to achieve an effective performance, organization management must focus on processes correlated to talent management for the purpose of solving problems and, more generally, enhancing performance. Such processes lie in talent attraction, talent retention, talent development and talent placement. The role of talent management appears vividly in worker performance enhancement and in fierce competition environments in organizations.

Organizational agility is concerned with surviving and flourishing in a competitive environment that is constantly and unpredictably changing through rapid market shifts as prompted by the introduction of products and services to customers Haskins, Shaffer, (2010).

Researchers have chosen the subject of talent management with its dimensions: talent attraction, talent retention, talent development and talent placement due to the importance of the subject. This importance lies in revealing the achievements of talent management strategies in organizational agility with employees in government institutions in the governorate of Ma'an.

\subsection{The Problem of the Study:}

With the rapid development that occurs in the world nowadays in the realms of economy, politics, and society, demand increases for creative and innovative activities and capabilities; it has become necessary for organizations to foster talent among members and employees in order to help them keep pace with development, managing and encouraging talent in order to sustain competitive status and dominance (Roni and Joshi, 2012).

Organizations are interested in providing whatever talents they possess with work toward their development and growth, in addition to the scientific and technological infrastructure necessary for building on such talents for leadership succession and institutional memory. In particular, employees who are not in leadership positions in an organization may thus expect attractive offers for positions of leadership or recruitment by competitors in the event that they demonstrate outstanding service. Consequently, organizations must endeavor to narrow down and/or eliminate 
gaps in their hierarchy of employee talent by gratifying demonstrations of talent duly and appropriately.

Talent management has become a leading strategy in organizational building processes by utilizing worker results to create competitive advantages within institutions. The problem of the study then is concerned with identifying the extent of talent management in governmental institutions in MA'AN in an attempt to understand these strategies' effects on organizational agility.

It is possible to display the problem of the study more clearly through the answering of the following question.

Question 1: How the major dimensions of talent management affect organizational agility?

Question 2: What is correlation between talent management and organization agility?

\subsection{Objectives of the study}

This study aims at revealing the effect of talent management achievement on organization's agility among employees of governmental agencies in Ma'an governorate. The main objective branches to the following sub objectives:

1-To identify the effect of talent management, along with its variables on organizational agility

2-To diagnosis the nature of correlation relationship between talent management and organizational agility, also to reveal the determinant factors as well..

3-To provide scientific and educated recommendations based on study's results to decision makers so as to have interest in, and adopt talent management strategies and organizational agility effectively and competently.

\subsection{Importance of the Study}

The importance of this study stems from its practical side, it is trying to identify the effect of talent management on organizational agility, in a time when organizations rely on talented human resources, and the importance of its management effectively and competently in various sectors. In theoretical side, the importance of the study stems from its discussion of a vital and new subject of human resources, due to the crucial role that it plays in business organizations in sum the importance of the study lies in the following considerations:

1- $\quad$ This study contributes in enriching this field of research and studies by which it may become a reference to upcoming researchers and people of concerned in talent management, and organizational agility. 
2- $\quad$ It is hopeful that current study benefits corporate management, and decision makers in the study's sample in investing in talent management, apply it in ideal manner through the utility of best practices, and to take advantage of exemplary and talented individuals' abilities.

\subsection{Hypotheses of the Study}

In order to achieve logic, built on accurate, scientific and sound methodological solution for the problem of the study, the following hypotheses have been articulated so as to be tested through various statistical approaches:

\section{The study's major null hypothesis:}

HO1: There is no statistically significant effect of talent management along with its variables (talent attraction, talent retention, talent development. talent placing), on organizational agility in accordance with its dimensions (decision making agility, practice agility, detection agility) in governmental agencies in the city of Ma,an.

There are several sub hypotheses branched out from the major hypothesis of the study:

HO1.1 There is no statistically significant effect of talent management along with its variables (talent attraction, talent retention, talent development. talent placing), on organizational agility according to decision making dimension, in governmental agencies in Ma'an.

HO1.2: There is no statistically significant effect of talent management along with its variables (talent attraction, talent retention, talent development. talent placing), according to practice agility dimension in governmental agencies in Ma'an.

HO1.3 : There is no statistically significant effect of talent management along with its variables (talent attraction, talent retention, talent development. talent placing), according to investment agility dimension in governmental agencies in Ma'an.

\subsection{The Model of the Study}

In order to achieve the objectives of the study, and to reveal relationship among the study's variables, researcher will use the following model. 
Table 1.

\begin{tabular}{|c|c|}
\hline Organizational Agility & Talent Management Strategies \\
\hline Decision MakingAgility & TalentAttraction \\
\hline PracticeAgility & Talent Retention \\
\hline Detection Agility & $\begin{array}{l}\text { Talent Development } \\
\text { Talent placing }\end{array}$ \\
\hline
\end{tabular}

\subsection{Theoretical Background of the Study}

Talent has become one of the important issues in human recourses management. It provoked the interest of many researchers trying to reveal many facts about this concept. In regard to the theoretical part of the issue, there are several researchers how see that certain individuals how considered to be talented because they possess abilities and exceptional capabilities which enable them to influence the organizations' competency and effectives (Vladescu, 2012). While others see the issue from practical perspective, namely, it is possible for any person to have influence in achieving the organizations objectives, such person can be called talented. Thus, management should not focus on such individuals or small group of those who own exemplary abilities, while others do not, because each individual in successful organizations owns salient and capacities which can be motivated and nurture by management in order for organization to acquire competitive advantage. Thus, talented person can be defined as any person who has more motivation, abide by rules and regulators and has effective performance by which organization's objectives can be achieved with unprecedented competency and efficiency. In regard to talent management's term, it appeared in late last century. It has several definitions, despite author's disagreement to find a universal definition. Horvathova (2011) defines talent management as a set of organization's activities which cares about acquiring, owning, development, motivate and retaining of talented employees in order to achieve the organization's objectives.

Chameant-Sonea et al (2011) define talent management as the utility of intertwined and connected a set of activities whereas, through such activities the organization works towards recruiting (attracting) retaining and development of talented individuals who the organization is in need for them, now and in future in order to achieve competitive advantage.

Waheet at al (2012) define talent management as management system responsible for determining the more important and sensitive matters in the 
organization. Such matters contributes to have organization achieve sustainable

Detection Agility: it is strategic observation of environment events which may have effect on organizational strategy, competition and future performance. Detection process includes activities such as acquiring information relevant to events which reflect environmental change and information technology relevant to organizational rules $\mathrm{Li}$, Linjie and Wang, Xing, (2010), Literature about the talent management is very rich due to the subject's importance, some authors discuss one or more aspects of talent management while using case studies such as Uren L. and Samuel J. 2007 who studied the influence of talent management and organizational learning on firm's sustainability. He uses Zain Company to achieve the objectives of his study. Kasasbeh proved that talent management and organizational learning have positive impact on Zain Company's sustainability. Similar results are shown by Siyam (2013) in their study talent management's supports organizational loyalty among faculty member of various Jordanian Universities as it is mentioned earlier, authors and researchers keep.

Researchers kept on conducting about countless subjects relevant with talent management and organizational agility using different titles for every study or research Rowland, M., (2011). For example we see one study about the discussed the extent of HR management through the availability of talent management core principles application in the city of Gaza this study was conducted among middle and upper management of the Islamic university . Result revealed the availability of primary principles of talented management however there was no proper application (Siam , 2013 ).

Hezaji et al (2012) tried to explore the extent of talent management among Lebanese employees at SETS company in Beirut , the result of study showed : 1- most of participant did not have any idea talent management strategies and process 2 - the is no talent management comprehensive strategy 3- there is mix of between HRSM and HRM, in this case it would be difficult for management to know talented employees and how to attract them , sustain and to develop talented employees . Kehinde, James, (2012). result showed the intention of employees to go through employment rotation that reflect positively on organization competency, while there is negative relationship between talent management and organization competency .

Hanif and Yunfei (2013) conducted study about the role of talent management and HRSM in talent sustaining result revived that the role which talent management place is inseparable part of HRM general strategy IQBAL et al (2013) study that talent management is not old subject stuffed in an old bottle, rather is to show the relationship between talent management different activities and HRM traditional practices, Also to show the emotional stability of employees and talent management practices 
and the effect of such practices on organizational performance, the study conducted with the participation of (201) Pakestani companies, results show that working force planning has positive effect on companies performance . Employee's rewards and recommendation have positive effect on companies' performance.

\subsection{Methodology of Study}

Researcher used critical descriptive approach because it is a proper method for such studies also analysis connection interpretation and resignation of relationships that connect a set of variables with each other are determined, relationship between two variables or more which can be measure the degree of the relationship . (Abu Zina and BATASH , 2007 ) Researcher relied on two sources to collect data for the study 1-Secondary sources the researcher used theoretical framework processing for researching in data sources, it is represented in previous literature review of university papers, researches and articles in addition to website books and Arabic and foreign specialized journals related to study subject.

2-Primary sources: A questionnaire was developed to be used as the study tool to collect the primary data of study sample.

\subsubsection{Population of the study}

Population of the study consists of the employees in the middle and upper levels in governmental units in Ma'an governorate. There were 152 employees' at all governmental institutions in Ma'an governorate.

Relevant literature, theoretical back ground and previous studies included were revewed. Based upon that a questionnaire was developed to be the primary data collection to questionnaire consists of the following parts:

Part one: Demographic elements such as: occupation education qualification, age, gender, occupation, works experience.

Part two: consists of terms to measure independent variable (talent management)

Part three: consists of items to measure dependent variable organizational agility

Questionnaires validity

To determine the extent of the questionnaire validity, the questionnaire was distributed on group of faculty members of public administration department, Ma'an University. To know the opinions and notes about the coordination of questionnaire and the extent with the goals The statistic styles utilize on study

The data was processed by using social science statistic program (SPSS V21) for answer the questions of study and testing the hypotheses, according to this statistical processing. 
1- Descriptive Statistic Measures: to describe the characteristics of study sample by percentages, answer the study questions and descending order.

2- $\quad$ Multiple Regression Analysis to test the power of study samples and the effect of independent variable with dimensions

3- $\quad$ Stepwise Multiple Regression Analysis to test independent variable with equation of prediction.

4- $\quad$ For test Variance Inflation Factor and Tolerance to make sure there is no high correlation between the independent variable. Skewness to make sure that the data follows the normal distribution.

\section{Answering the Study's Questions}

In order to answer the study's questions arithmetic means and standard deviation of responses have been computed as it is shown in table (2).

Means and standard deviations of all variables "talent management, organizational agility is relatively high.Means for variables" talent management is (3.81). Talent recruiting came in the first place with means of (3.86), followed by talent sustaining by (3.82), while talent development came third by means of (3.89)In the last place talent placing with means of (3.78).

In regard to means and standard deviation of organizational agility it came in very high degree. Whereas the total means is $3.74 \mathrm{v}$ The decision making agility dimension occupies first place by 3.78 In the second place practice agility dimension by 3.74 means . Detection agility occupied the last place 3.70 .

The talent management dimensions

\begin{tabular}{|c|c|c|c|c|c|}
\hline Series & Dimension name & means & $\begin{array}{c}\text { Standard } \\
\text { Deviation }\end{array}$ & $\begin{array}{c}\text { rank by } \\
\text { means }\end{array}$ & item level \\
\hline 1 & Talent recruiting & 3.86 & 0.66 & 1 & High \\
\hline 2 & Talent sustaining & 3.82 & 0.67 & 2 & High \\
\hline 3 & $\begin{array}{c}\text { Talent } \\
\text { development }\end{array}$ & 3.80 & 0.60 & 3 & High \\
\hline 4 & Talent placing & 3.78 & 0.64 & 4 & High \\
\hline & Total average & 3.81 & 0.64 & - & High \\
\hline
\end{tabular}

The dimensions of organizational agility

\begin{tabular}{|c|c|c|c|c|c|}
\hline 1 & $\begin{array}{c}\text { Decision making } \\
\text { agility }\end{array}$ & 3.78 & 0.66 & 1 & High \\
\hline 2 & Practice agility & 3.74 & 0.69 & 2 & High \\
\hline 3 & Detecting agility & 3.70 & 0.61 & 3 & Medium \\
\hline & Total average & 3.74 & 0.66 & - & High \\
\hline
\end{tabular}




\section{Hypotheses Testing}

Major Hypothesis: there is no statistically significant effect of talent management along with its variables( Talent recruiting, Talent sustaining, Talent development, Talent placing) on organizational agility according to its dimensions: Decision making agility, Practice agility, Detecting agility in government agencies in Ma'an governorate

In order to test this hypothesis, researcher examined criteria to apply regression namely natural distribution of data (Skewness) and independent variables ( Talent Management Variables ) also to be sure that there is no multi co linearity among independent variables as its shown in table bellow

Table 2. The curve coefficient and result of VIP of tolerance for talents management

\begin{tabular}{|l|l|l|l|}
\hline $\begin{array}{l}\text { Independent } \\
\text { variable }\end{array}$ & Curve coefficient & VIF & Tolerance \\
\hline Talent recruiting & -0.84 & 5.35 & 0.19 \\
\hline Talent sustaining & -1.16 & 3.07 & 0.33 \\
\hline Talent development & -0.69 & 5.36 & 0.19 \\
\hline Talent placing & -1.44 & 2.45 & 0.41 \\
\hline
\end{tabular}

Results show the value of curve coefficient is $(-0.84)$ to determine talent need and $(=1.44)$ for talent placing. These values are considered to be acceptable where as its possible to infer that talent management dimensions data is close to natural distribution.

In regard to multi Co Linearity, it has been shown that the largest value 5.36 for talent development. It must be noted that the value of difference within several standards do not exceed the value of(10)which shows a strong correlation the independent variable in regard to allowed variation test . Whereas, the computed value is greater than $(0.10)$. This indicates that there is no linearity correlation problem among independent variables. As it is shown in table (3)

Table 3. Results of multiple linear Regression of talent management for organizational agility in governmental agencies in Ma'an

\begin{tabular}{|l|l|l|l|l|l|}
\hline $\begin{array}{l}\text { Independent } \\
\text { variable }\end{array}$ & $B$ & $\begin{array}{l}\text { Standard } \\
\text { error }\end{array}$ & Beta & $\mathrm{t}$ & Sigt. \\
\hline Talent recruiting & 0.080 & 0.029 & 0.098 & $* 2.82$ & 0.005 \\
\hline $\begin{array}{l}\text { Talent } \\
\text { development }\end{array}$ & 0.171 & 0.033 & 0.195 & $* 5.086$ & 0.000 \\
\hline Talent sustaining & 0.128 & 0.029 & 0.180 & $* 4.678$ & 0.000 \\
\hline Talent placing & 0.233 & 0.032 & 0.269 & $* 6.79$ & 0.000 \\
\hline
\end{tabular}

(*) Indicates the presence of statistically significant relationship.

Results show the presence of statistically significant effect of talent management in organizational agility in governmental agencies in Ma'an. In (Beta)and (t) reveal that talent management dimensions consecutively have statistically significant effect in the dependent variable of talent management 
because of the high value of computed $(t)$ shown in the above table at $(\alpha \leq$ 0.05) and efficient impact of statistically significance of (Beta) HO1.1

There is no statistically significant effect of talent management with its variables (talent recruiting, talent sustaining, talent development, talent placing) on organizational agility according to (decision making agility) dimension in governmental institutions in Ma'an

Table 4.Multiple regression analysis results to test the effect of talent management on decision making agility

\begin{tabular}{|l|l|l|l|l|l|}
\hline Talents management & B & $\begin{array}{l}\text { Standard } \\
\text { error }\end{array}$ & Beta & $\begin{array}{l}\text { Computed } \\
\text { t }\end{array}$ & $\begin{array}{l}\text { Statistically } \\
\text { significance }\end{array}$ \\
\hline Talent recruiting & 0.235 & 0.064 & 0.252 & $* 3.741$ & 0.000 \\
\hline Talent sustaining & 0.365 & 0.061 & 0.442 & $* 6.551$ & 0.000 \\
\hline Talent development & 0.265 & 0.063 & 0.230 & $* 4.276$ & 0.000 \\
\hline Talent placing & 0.216 & 0.059 & 0.210 & $* 3.850$ & 0.000 \\
\hline
\end{tabular}

*Has statistically significance

Table (4) shows through the values of $(\mathrm{t})$ that the sub variables (talent recruiting, talent sustaining, talent development, talent placing) have an effect on decision making agility, whereas the computed (t) are:3.741,6.551,4.276,3.850 consecutively. Which are abstract values at $\alpha \leq$ $0.05 S$ Thus, the first hypothesis is rejected, while the alternative hypothesis is accepted. This hypothesis states that: There is statistically significant effect of talent management with its variables (talent recruiting, talent sustaining, talent development, talent 8placing) on organizational agility according to decision making agility in governmental institutions in Ma'an HO.1.2 There is no statistically significant effect of talent management along with its variables (talent recruiting, talent sustaining, talent development, talent placing)on organizational agility according to practice agility at governmental institutions in Ma'an

Table 5

\begin{tabular}{|l|l|l|l|l|l|}
\hline Talents management & B & Standard error & Beta & Computed & S significance \\
\hline Talent recruiting & 0.240 & 0.060 & 0.231 & $* 3.977$ & 0.000 \\
\hline Talent & 0.311 & 0.059 & 0.086 & $* 5.605$ & 0.000 \\
\hline Talent development & 0.219 & 0.219 & 0.244 & $* 3.694$ & 0.000 \\
\hline Talent placing & 0.214 & 0.214 & 0.199 & $* 3.610$ & 0.000 \\
\hline
\end{tabular}

Table shows that the minor variables and related with ( talent recruiting , talent sustaining, talent development, talent placing ) also it had effect in practice agility, where the value of $(\mathrm{t})$ is $(3.610,3.694,5.605,3.977)$ respectively, its abstract values in $(\alpha \leq 0.05)$. based on the above, the first theory is reject but the other theory is accept, which said there is no statically significant off effect of talent management along with its variable ( Talent recruiting, talent sustaining, Talent development, Talent placing ) 
on organizational agility according to practice agility in the governmental institutions in Ma'an .

HO1.3 : There is no statistically significant effect of talent management along with its variables (talent recruiting, talent sustaining, talent development, talent placing) on organizational agility according to dictating agility at governmental institutions in Ma'an.

Table 6.

\begin{tabular}{|l|l|l|l|l|l|}
\hline Talents management & $\mathrm{B}$ & Standard error & Beta & Computed & S significance \\
\hline Talent recruiting & 0.209 & 0.052 & 0.205 & $* 4.677$ & 0.000 \\
\hline Talent sustaining & 0.337 & 0.049 & 0.366 & $* 8.444$ & 0.000 \\
\hline Talent development & 0.201 & 0.059 & 0.155 & $* 4.675$ & 0.000 \\
\hline Talent placing & 0.189 & 0.050 & 0.183 & $* 3.912$ & 0.000 \\
\hline
\end{tabular}

Table 6 shows with (t) test variables (,talent recruiting, talent sustaining, talent development, talent placing ) have effect on detection agility, where as computed (t) value are : 3.912,4.675,8.444,4.677) respectively its abstract values in $(\alpha \leq 0.05)$. based on the above, the first theory is reject but the other theory is accept, which said there is no statically significant off effect of talent management along with its variable ( Talent recruiting, talent sustaining, Talent development , Talent placing ) on organizational agility according to practice agility in the governmental institutions in Ma'an .

\section{Results}

These results show that the study's participants' visualization of talent management along with its dimensions (talent recruiting, talent sustaining, talent development, talent placing) is very high.

3- Organizational agility with its dimensions (decision making agility, practice agility, detection agility) among participants is very high.

4- Sub variables ( talent recruiting, talent sustaining, talent development, talent placing) have effect on decision making agility

5- Sub variables (talent recruiting, talent sustaining, talent development, talent placing) have effect on practices agility.

6- Sub variables ( talent recruiting, talent sustaining, talent development, talent placing) have effect on detection agility

\section{Recommendation}

The study recommends the following:

1. It is necessary to have governmental agencies be concerned of and adopt talent management due to its positive effects on organizational agility enhancement. 
2. Have effective strategies built upon scientific standards to discover talented people and to empower them.

3. To create specialized bureau that nurture talented persons within public sector. Also to encourage investment in talented youth, and to create assessment mechanism to recognize them.

4. Keep pace with contemporary managerial thoughts in talented management, promote modern learning and have whatever it takes to discover their abilities, Pay attention to careers as an instrument to enhance talents with individuals.

5. To conduct further studies in this context in the Arab world in general, and Jordan in particular.

\section{References:}

1. Abu Zina, Farid, Al-Batsh (2007), Research Methods, Statistical Research and Analysis Design, Amman, Jordan.

2. Câmpeanu-Sonea, E., Sonea A., Gabor-Supuran, R., Mureşan, A. (2011), "Organizational Competence - A Development Framework", Management and Marketing, Vol. 6, No. 2, PP 301-318.

3. Hanif, Muhammad Imran, and Yunfei, Shao, (2013), "The role of talent management and HR generic strategies for talent retention", African Journal of Business Management, Vol. 7, No. 29, PP 28272835.

4. Horváthová, Petra, (2011), "The Application of Talent Management at Human Resource Management in Organization", 3rd International Conference on Information and Financial Engineering, IPEDR Vol. 12 IACSIT Press, Singapore.

5. Haskins, M.E., and G.R. Shaffer, (2010), "A talent development framework: Tackling.

6. Source: Park, Young Ki, (2011), The dynamics of opportunity and threat management in turbulent environments: the role information technologies , Doctor Dissertation, P. 28.

7. Iqbal, Sarmad, Qureshi, Tahir Masood, Khan, M. Aslam, and Hijazi, Syed Tahir, (2013), "Talent management is not an old wine in a new bottle", African Journal of Business Management, Vol. 7, No. 35, PP 3609-3619.

8. Kehinde, James Sunday, (2012), "Talent Management: Effect on Organizational Performance", Journal of Management Research, Vol. 4, No. 2, PP 178 - 186.

9. Li, Linjie and Wang, Xing, (2010), "The Strategy of Talent Localization in Multinational Corporations", International Journal of Business and Management, Vol. 5, No. 12, PP 2016-219.

10. Rowland, M., (2011), "How to cement a diversity policy: The key 
role of talent development", Human Resource Management International Digest, Vol. 19, No. 5: Pp 36 - 38.

11. Rani, Anupam, and Joshi, Upasna, (2012), "A Study of Talent Management as a Strategic Tool for the Organization in Selected Indian IT Companies", European Journal of Business and Management, Vol. 4, No. 4, PP 20-29.

12. Uren L. and Samuel J. 2007, "From talent compliance to talent commitment", Strategic HR Review, Vol. 6, No. 3, PP 32-35.

13. Vládescu, Angela, (2012), "The Possibility Of Implementing Talent Management in The Public Sector", Management \& Marketing Challenges for the Knowledge Society, Vol. 7, No. 2, PP 351-362.

14. Waheed, Sajjad, Zaim, Abdülhalim, and Zaim, Halil, (2012), "Talent Management in Four Stages", The USV Annals of Economics and Public Administration, Vol. 12, Issue 1(15), PP 130-137. 